\title{
REFLEXÕES SOBRE AS POLÍTICAS PÚBLICAS PARA A EDUCAÇÃO DE PESSOAS JOVENS E ADULTAS: DESVELANDO CONTRADIÇÕES
}

Jerry Wendell Rocha Salazar ${ }^{1}$

Marcelo Pagliosa Carvalho ${ }^{2}$

\section{RESUMO}

Neste artigo desvela-se as contradições das políticas públicas para a Educação de Pessoas Jovens e Adultas (EPJA) a partir da perspectiva materialista histórico-dialética. Realiza-se uma discussão acerca das políticas públicas federais desenvolvidas no Brasil desde a década de 1950. Trata-se de pesquisa bibliográfica, visto que se constitui por meio do levantamento de literatura especializada. Utiliza-se para análise da EPJA as categorias dialéticas: historicidade, totalidade e contradição. Elege-se como aporte teórico-metodológico as contribuições de Marx e Engels (1989), Mészáros (2008), Frigotto (2005), Saviani (2008), Freire (2002, 2005), Haddad (2002), entre outros. Os resultados nos desafiam a encontrar novas possibilidades para se pensar a EPJA que fundamentalmente esteja compromissada com a emancipação dos sujeitos que dela fazem parte.

Palavras-chave: Educação de Pessoas Jovens e Adultas. Políticas Públicas para a EPJA. Políticas Públicas Educacionais.

\footnotetext{
1 Mestre em Educação pela Universidade Federal do Maranhão. Professor-formador do Centro Avançado de Apoio à Educação CAAED/SEMED-São Luís. Professor externo da Universidade Federal do Maranhão. Participa do Grupo de Pesquisa em Escola, Currículo e Formação Docente-PPGE/UFMA. ORCID: https://orcid.org/0000-0001-8778-7149. E mail : jerry.salazar@discente.ufma.br.

2 Doutor em Educação pela Universidade de São Paulo (USP). Professor Associado II da Universidade Federal do Maranhão (UFMA). ORCID: http://orcid.org/0000-0002-2498525X. E-mail: marcelo.pagliosa@yahoo.com.br.
} 


\section{REFLECTIONS ON TEACHING YOUNG AND ADULT LEARNERS: DIALOGUE AMONG CRITICAL THEORIES AND ANDRAGOGY}

\section{ABSTRACT}

This article reveals the contradictions of public policies for the Education of Young People and Adults (EPJA) from the historicaldialectical materialist perspective. There is a discussion about federal public policies developed in Brazil since the 1950s. This is bibliographical research, as it is constituted through a survey of specialized literature. The following dialectical categories are used to analyze the EPJA: historicity, totality and contradiction. The theoretical-methodological contributions of Marx and Engels (1989), Mészáros (2008), Frigotto (2005), Saviani (2008), Freire (2002, 2005), Haddad (2002), among others, are chosen. The results challenge us to find new possibilities to think about the EPJA that is fundamentally committed to the emancipation of the subjects that are part of it.

Keywords: Education of Young People and Adults. Public Policies for EPJA. Educational Public Policies.

\section{REFLECTORES SOBRE LA EDUCACIÓN DE PERSONAS NIÑAS Y ADULTOS: DESVELANDO CONTRADICACIONES}

\section{RESUMEN}

Este artículo revela las contradicciones de las políticas públicas para la Educación de Jóvenes y Adultos (EPJA) desde la perspectiva histórico-dialéctica materialista. Se discute sobre las políticas públicas federales desarrolladas en Brasil desde la década de 1950. Se trata de una investigación bibliográfica, ya que se constituye a través de un relevamiento de la literatura especializada. Para analizar la EPJA se utilizan las siguientes categorías dialécticas: historicidad, totalidad y contradicción. Se eligen los aportes teórico-metodológicos de Marx y Engels (1989), Mészáros (2008), Frigotto (2005), Saviani (2008), Freire (2002, 2005), Haddad (2002), entre otros. Los resultados nos retan a encontrar nuevas posibilidades para pensar en la EPJA que 
apuesta fundamentalmente por la emancipación de los sujetos que la integran.

Palabras clave: Educación de jóvenes y adultos. Políticas públicas para EPJA. Políticas Públicas Educativas.

\section{INTRODUÇÃO}

Parece-nos pertinente iniciar este artigo tratando do método que lançamos mão para a análise do objeto de estudo aqui tratado: a Educação de Pessoas Jovens e Adultas ${ }^{3}$ (EPJA). A priori, esclarecese que, embora naturalista e empírico, o método histórico dialético não é positivista, mas sim realista. Assim, a essência da crítica de Marx ao "materialismo contemplativo" situa-se no fato de que este dessocializa e des-historiciza a realidade.

Para Marx, a História sempre se aperfeiçoa, por estar em constante movimento de transformação. O motor desse movimento é a contradição que existe em tudo: fenômenos, coisas ou processos. A contradição não é uma simples oposição, como entre preto e branco. A contradição faz com que tudo sofra mudanças profundas.

Em "Ideologia Alemã (1845-1846)", Marx e Engels (1989) identificam o caráter ontológico do método materialista histórico dialético, quando se postula que o ponto de partida para a transformação da sociedade é a mudança do indivíduo. Não há mudança sem que esta ocorra antes nas relações sociais.

Em face do exposto, este artigo discute a EPJA a partir dos desvelamentos do materialismo histórico dialético, considerando a historicidade, a totalidade e as contradições que envolvem essa modalidade de ensino no Brasil.

\footnotetext{
${ }^{3}$ Adotaremos ao longo deste texto o termo "Educação de Pessoas Jovens e Adultas - EPJA" seguindo as orientações da Cátedra da UNESCO e, sobretudo, por compreendermos que a utilização do termo "pessoas" abarca a dimensão do sujeito enquanto ser humano. Além de apontar para a afirmação dos direitos das mulheres à educação, não flexionando para o gênero masculino. Porém, manteremos o termo "Educação de Jovens e Adultos EJA" nos momentos em que estivermos trabalhando com esta denominação utilizada por autores/as analisados/as ou citada nas legislações.
} 
No Brasil, segundo dados obtidos na Pesquisa Nacional por Amostra de Domicílios Contínua (PNAD Contínua) realizada em 2019 e divulgada em 2020, a taxa de analfabetismo das pessoas de 15 anos ou mais de idade foi estimada em $6,6 \%$, o que equivale a 11 milhões de brasileiros analfabetos (IBGE, 2019). Insere-se nesse contexto o fato de a EPJA vir apresentando, ao longo de vários anos, constantes e sucessivas reduções no seu número de matrículas.

O Censo Escolar 2020, divulgado em 2021 pelo Instituto Nacional de Estudos e Pesquisas Educacionais Anísio Teixeira (INEP), apontou queda de $8,3 \%$ no número de matrículas de EPJA no País, o que representa 270 mil estudantes a menos nas salas de aula. A redução no primeiro e segundo segmento (nível fundamental) registrou queda de 9,7\% (equivalente a 187,4 mil matrículas), enquanto nas matrículas do terceiro segmento (nível médio) a redução foi $6,2 \%$ (83,5 mil matrículas). Os dados da pesquisa apontam 1,5 milhão de estudantes de 14 a 17 anos sem frequentar a escola, ou seja, a educação brasileira continua "fabricando" futuros demandantes de cursos de EPJA, ao não garantir o direito humano à educação de crianças e adolescentes nas idades esperadas.

Diante desse cenário, podemos depreender que a maneira como um país trata a educação, fornece indícios sobre que tipo de sociedade se deseja construir e sobre que tipo de seres humanos pretende-se formar. Quando se fala em direito à educação, fala-se de direitos sociais do ser humano, fala-se de direitos humanos. Não podemos defender o direito à educação sem associá-lo aos outros direitos (GADOTTI; ROMÃO, 2013).

Esse texto organiza-se em um conjunto de reflexões dispostas da seguinte forma: além da introdução e conclusão, possui outras três seções. Na primeira seção, considerando a categoria dialética da historicidade, traçamos o histórico das políticas públicas de EPJA no Brasil. Na segunda seção, evocamos a categoria da totalidade para compreender a concepção de educação de pessoas jovens e adultas no Brasil. Já na terceira seção, abordamos as contradições e as possibilidades da EPJA. 


\section{HISTÓRICO DA EJA NO BRASIL}

Em fins da década de 1950 constatou-se o fato de que as várias campanhas nacionais voltadas para a educação das pessoas adultas realizadas até então não haviam alcançado os resultados esperados em termos de combate ao analfabetismo ${ }^{4}$. A partir desta constatação, tem início um novo momento na Educação das Pessoas Jovens e Adultas (EPJA), que teve como marco principal o II Congresso Nacional de Educação de Adultos (CNEA), realizado em 1958. As ideias do educador Paulo Freire, que seriam sistematizadas em 1962, começaram a ganhar força e a provocar um período de muita reflexão sobre o social na educação. Vários grupos sociais enxergavam na aplicação das propostas do educador pernambucano uma maneira de o povo participar politicamente na sociedade brasileira (ROMANELLI, 1986; HADDAD, 1991).

Nesse mesmo período, além das novas perspectivas metodológicas para a EPJA, ocorrem vários movimentos sociais ligados à educação e à cultura popular: o Movimento de Educação de Base (MEB), ligado à Conferência Nacional dos Bispos do Brasil (CNBB), o Centro Popular de Cultura (CPC), da União Nacional dos Estudantes (UNE), o Movimento de Cultura Popular (MCP), criado em Recife/PE e depois expandido pelo País, e a campanha "De Pé no Chão também se aprende a ler", criada pela prefeitura de Natal/RN.

Em janeiro de 1964, foi criado o Plano Nacional de Alfabetização (PNA), que pretendia alfabetizar, em dois anos, cinco milhões de adultos por meio do chamado "Método Paulo Freire", utilizando recursos e assistência técnica da união. O PNA marcava então a incorporação mais ampla, no nível do governo federal, das práticas de educação e cultura popular que haviam ganhado força desde 1958. Com o Golpe Civil-Militar de 1964, os movimentos de educação e cultura popular foram reprimidos e extintos, muitos de

\footnotetext{
${ }^{4}$ As campanhas nacionais realizadas até então foram a Campanha de Educação de Adolescentes e Adultos (CEAA) de 1947, a Campanha Nacional de Educação Rural de 1952, a Campanha Nacional de Erradicação do Analfabetismo de 1958 e o Sistema Radioeducativo (SIRENA) de 1958.
} 
seus dirigentes foram presos, seus ideais foram censurados ${ }^{5}$. O PNA foi extinto, seus dirigentes também foram presos e seus materiais apreendidos.

Além da repressão contra os movimentos de educação popular, o Estado autoritário procurou incentivar programas para a educação da população com o objetivo de neutralizar os efeitos das ideias educacionais anteriores a 1964, de controlar os grupos populares, servindo-se desses para legitimar o novo poder político.

O Movimento Brasileiro de Alfabetização (MOBRAL) foi criado pelos militares no início da década de 1970, pois estes acreditavam que a EJA não poderia ser abandonada pelo Estado, uma vez que era um canal importante de mediação com a sociedade. Todavia, essa educação deveria servir aos interesses hegemônicos do modelo sócio, político e econômico dos militares. O MOBRAL, portanto, foi idealizado em oposição às ideias e às práticas pedagógicas produzidas pelos movimentos de educação e cultura popular anteriores a 1964. Essa campanha de alfabetização foi complementada pelo Ensino Supletivo de $1^{\circ}$ e $2^{\circ}$ graus (regulamentado pela Lei $n^{\circ}$ 5.692/1971).

A partir do final dos anos 1970, passa a ser verificada uma reorganização política da população, que culminaria, na década seguinte, com a derrota da Ditadura Empresarial-Militar (1964-1985). Começam a emergir movimentos sociais que se organizam em torno de melhores condições de vida, demandando direitos e serviços que influenciariam as políticas públicas no período constituinte. Nesse contexto, uma das formas de articulação da população era a reivindicação de direitos educacionais, devido às fragilidades das políticas adotadas pelo Estado nessa área. Na EPJA, a falta de oferta adequada e a péssima qualidade dos serviços oferecidos impulsionaram a criação de núcleos que desenvolviam a escolarização para essa parcela da população. Esses núcleos, geralmente, eram ligados a setores progressistas da Igreja Católica.

Nos anos de 1980, ganha força o tema da participação da sociedade civil nos espaços públicos de decisão política, durante o

\footnotetext{
${ }^{5}$ Somente o MEB, por suas ligações com a CNBB, foi mantido, mas teve que mudar suas propostas para se adequar ao novo governo, tornando-se, na década de 1970, mais um instrumento de evangelização do que de educação popular.
} 
processo de transição do regime autoritário para o democrático. A luta por participação popular se amplia, em especial durante o período constituinte, por meio da pressão e da proposição dos setores organizados da sociedade para incorporar na Carta Magna canais de participação do povo na gestão pública. É forte, também, a luta pela ampliação do atendimento educacional público no País. Nesse contexto, há uma pressão crescente para que o Estado crie condições para a escolarização formal de jovens e adultos.

A omissão do poder público no atendimento educacional gerou uma série de reivindicações de educadores e movimentos sociais, que defendiam o direito à escolarização e que lutavam, também, para que o Estado garantisse este direito para o público jovem e adulto. Nesse processo, os setores em luta tinham, entre outras, duas importantes referências: a educação popular e o conceito de libertação, tão propalados por Paulo Freire; a transformação social e o conceito de hegemonia, baliza do pensamento gramsciano.

Arroyo (2005) destaca que a EJA e os sujeitos que lutam para o reconhecimento do seu direito tinham/têm a perspectiva de intervenção, de transformação da sociedade:

[...] A EJA sempre aparece vinculada a um outro projeto de sociedade, um projeto de inclusão do povo como sujeito de direitos. Foi sempre um dos campos da educação mais politizados, o que foi possível por ser um campo aberto, não fechado e nem burocratizado, por ser um campo de possíveis intervenções de agentes diversos da sociedade, com propostas diversas de sociedade e do papel do povo (ARROYO, 2005, p. 31).

As lutas no campo político e/ou educacional, que emergiram no final da década de 1970 e ganharam força nos anos 1980, vão se refletir e influenciar a CF/1988. Essas ações, intensificadas durante o processo constituinte, pressionaram o Estado para que, dentre outras questões, reconhecesse os direitos educacionais da população jovem e adulta. A CF/1988 acaba responsabilizando o poder público por assegurar o direito ao ensino fundamental para a população jovem e 
adulta e estipula um prazo de dez anos para a erradicação do analfabetismo.

$\mathrm{Na}$ redemocratização, o Movimento Brasileiro de Alfabetização (MOBRAL), desenvolvido durante o período autoritário (1964-1985), foi suprimido e substituído pela Fundação Educar, que tinha o papel de órgão de fomento e de apoio técnico por meio de parcerias e não mais através da ação direta. O governo de Fernando Collor de Mello (1990-92), o primeiro eleito por voto direto após o regime militar, extinguiu a Fundação Educar. Porém, dentre outros desafios, esse governo teria de cumprir o Artigo 214 da CF/1988 e o Artigo 60 do Ato das Disposições Constitucionais Transitórias (ADCT):

Art. 214 - A lei estabelecerá o plano nacional de educação, de duração plurianual, visando à articulação e ao desenvolvimento do ensino em seus diversos níveis e à integração das ações do Poder Público que conduzam à:

I - erradicação do analfabetismo;

II - universalização do atendimento escolar;

III - melhoria da qualidade do ensino;

IV - formação para o trabalho;

V - promoção humanística, científica e tecnológica do país.

Art. 60 (ADCT) - Nos dez primeiros anos da promulgação da Constituição, o Poder Público desenvolverá esforços, com a mobilização de todos os setores organizados da sociedade e com a aplicação de, pelo menos, cinqüenta por cento dos recursos a que se refere o Art. $212^{6}$ da Constituição, para eliminar $\mathrm{o}$ analfabetismo e universalizar o ensino fundamental.

Assim, segundo a Lei Maior, o analfabetismo tinha data para ser eliminado: 1998. Havia, ainda, a estipulação de recursos para esse fim. Apesar das dificuldades e dos esforços necessários para cumprir tal meta e universalizar o ensino fundamental, a legislação firmou

${ }^{6}$ O Art. 212 da CF/1988, dentre outras coisas, é o que vincula os recursos provenientes da arrecadação de impostos para a área educacional, a saber: a União, nunca menos de $18 \%$ e os estados, o Distrito Federal e os municípios 25\%, no mínimo. 
uma intencionalidade política, estabeleceu um horizonte, reconhecendo a necessidade de se instalar no plano dos direitos um caminho para superar uma flagrante injustiça social (HADDAD, 2001).

Os movimentos sociais que lutam pela garantia do direito à educação do público jovem e adulto destacam a necessidade de políticas específicas para o atendimento dessas pessoas. Salienta-se, com razão, que essa luta ultrapassa o cenário educacional. São questões ligadas à identidade coletiva de grandes contingentes populacionais brasileiros:

Os jovens-adultos populares não são acidentados ocasionais que, ou gratuitamente, abandonaram a escola. Esses jovens e adultos repetem histórias longas de negação de direitos. Histórias coletivas. As mesmas de seus pais, avós, de sua raça, gênero, etnia e classe social. Quando se perde essa identidade coletiva, racial, social, popular dessas trajetórias humanas e escolares, perde-se a identidade da EJA e passa a ser encarada como mera oferta individual e de oportunidades pessoais perdidas [...] (ARROYO, 2005, p. 30)

Nos anos 1990, um cenário diferente do que ocorrera nos anos 1980 se delineia para a EPJA. A seguinte passagem do texto de Haddad (2002) fornece uma noção mais exata de como essa modalidade de ensino passaria a ser intencionalmente tratada a partir dessa época:

Deixem os velhinhos morrerem em paz! Deixem os velhinhos morrerem em paz!" Assim se pronunciou Darcy Ribeiro ${ }^{7}$, [...] no encerramento do Congresso Brasileiro organizado pelo GETA - Grupo de Estudos e Trabalhos em Alfabetização em 1990, por ocasião das mobilizações que marcaram o Ano Internacional

\footnotetext{
${ }^{7}$ Antropólogo de renome mundial, ocupou, entre outros cargos, o de vice-governador do Estado do Rio de Janeiro (1982). Foi cumulativamente Secretário de Estado da Cultura e coordenador do Programa Especial de Educação. Participou da criação e desenvolvimento dos Centros Integrados de Educação Pública (CIEP). Na época, era senador pelo Partido Democrático Trabalhista (PDT-RJ). A Lei de Diretrizes e Bases da Educação Nacional (Lei n 9.394, de 20/12/1996) é também conhecida como "Lei Darcy Ribeiro", por ter como um de seus pilares o projeto desse autor.
} 
da Alfabetização. Darcy, firme, falador incansável, argumentava, diante do seu amigo Paulo Freire, que assistia à sua performance na mesma mesaredonda, no auditório da antiga Escola Caetano de Campos.

Pode-se dizer que ali, por sua ousadia, Darcy inaugurava uma nova etapa de desqualificação da educação de pessoas jovens e adultas no âmbito das políticas públicas, revertendo um movimento inclusivo dos direitos por educação dos últimos cinqüenta anos (HADDAD, 2002, p. 111)

Assim, o discurso de Darcy Ribeiro sinalizava mais do que mera opinião pessoal sobre a "educação" que seria proporcionada aos jovens e adultos com pouca ou nenhuma escolaridade: ele indicava como a EPJA seria tratada na nova configuração do Estado em absoluto desrespeito aos direitos sociais. $O$ enfraquecimento e a desqualificação dessa modalidade de ensino nessa década passaram por dois aspectos principais e concomitantes:

a) a retirada - ou pelo menos a tentativa de retirada de alguns dos direitos que os jovens e adultos haviam conseguido, principalmente na CF/1988;

b) o desenvolvimento de programas ou campanhas para jovens e adultos de cunho emergencial e compensatório ${ }^{8}$, tão recorrentes na história da EPJA.

O governo de Fernando Collor de Mello lançou o Plano Nacional de Alfabetização e Cidadania (PNAC, 1991), dando a entender que a EPJA seria uma prioridade. Todavia, a desfaçatez que o marcou repercutiu também no PNAC, que praticamente não saiu do papel. Haddad (2001) afirmou, com razão, que nesse governo a EJA sofre uma inflexão no que se refere às garantias na CF/1988.

Com a posse de Itamar Franco (1992-1994), logo após o impeachment de Collor, adotou-se uma nova postura, de fazer

8 Entendemos por medidas emergenciais e compensatórias aquelas iniciativas tomadas sem a preocupação de resolver de forma sistemática e definitiva o atendimento de direitos sociais, no caso, o direito à educação. Em geral, elas são implantadas na forma de campanhas ou programas, pretensamente provisórios, visando a amenizar demandas que, se não atendidas, ocasionam denúncias e protestos de setores sociais organizados. Tais iniciativas tendem a se tornar perenes. 
cumprir o que estava estabelecido em lei, e, apesar das metas para o atendimento dos jovens e adultos analfabetos serem ainda pequenas, o governo sinalizava, pelo menos no discurso, que a EPJA continuaria sendo uma prioridade. Com a subida de Fernando Henrique Cardoso (FHC - 1995-2002) ao poder, esse quadro muda:

\begin{abstract}
A situação mudou com a redução dos recursos para as políticas sociais imposta pelo modelo neoliberal adotado pelos governos de Fernando Henrique Cardoso (1995/98 e 1999/02). A EJA passou a ser uma política marginal, em especial para o governo federal que define, progressivamente, a sua concepção sobre o 'regime de colaboração', entendido agora como uma ação centralizada de coordenação pelo governo federal e repasse de execução das políticas da educação básica para Estados e municípios, com acentuada sobrecarga desses últimos (ARELARO; KRUPPA, 2002, p. 94).
\end{abstract}

No início dos anos de 1990, já se observa uma influência maior do Fundo Monetário Internacional, do Banco Mundial e das formulações neoliberais nas políticas educacionais, em especial nos governos de FHC. Adota-se uma política de ajuste do Estado, de enxugamento das contas públicas, onde se destaca a retração de gastos em setores sociais, na tentativa de apagar a ideia da educação pública como direito, principalmente na área da EPJA. Passa a vigorar uma despolitização generalizada e essa modalidade de ensino é tratada de maneira assistencialista, como política compensatória coadjuvante, conforme argumentam Haddad e Di Pierro (2000).

De acordo com essa política de cunho neoliberal, na educação, o país deveria garantir eficiência e racionalização, entendidas na dimensão estrita da relação custo-benefício, segundo as "modernas" regras do mercado:

O discurso da globalização [...] esconde, porém, que a sua é a ética do mercado e não a ética universal do ser humano, pela qual devemos lutar bravamente se optarmos, na verdade, por um mundo de gente. [...] O discurso ideológico da globalização procura disfarçar que ela vem 
robustecendo a riqueza de uns poucos e verticalizando a pobreza e a miséria de milhões. $O$ sistema capitalista alcança no neoliberalismo [...] o máximo de eficácia de sua malvadez intrínseca (FREIRE, 2002, p. 144).

A política de focalização no ensino fundamental e apenas para crianças e adolescentes na idade esperada tem que ser entendida dentro do contexto neoliberal. Isso pode ser constatado na aprovação da Emenda Constitucional no 14/1996, que instituiu o Fundo de Manutenção e Desenvolvimento do Ensino Fundamental e de Valorização do Magistério (Fundef). Dentre outros pontos, tal Emenda suprimiu o artigo das Disposições Transitórias da CF/1988 que responsabilizava o governo e a sociedade civil por erradicarem o analfabetismo e universalizarem o ensino fundamental em dez anos.

Além disso, mesmo que inconstitucional, o veto presidencial ao inciso II, $\S 1^{\circ}$, do Art. $2^{\circ}$ da Lei 9.424/1996 excluiu as matrículas de EJA do total das matrículas que podem fazer jus aos recursos do Fundef. Tal veto gerou uma situação capciosa: não havia nenhuma barreira para o uso dos recursos deste fundo na EJA, o que não podia acontecer era computar suas matrículas para o recebimento de recursos. Ao não considerar as matrículas da modalidade em discussão para o repasse de verbas, o Fundef acabou marginalizando ainda mais a educação oferecida ao público jovem e adulto.

Nos governos de FHC, O MEC passou a desenvolver programas de EPJA em regime de parcerias, sendo que nem a própria coordenação desses programas ficava a cargo do ministério. Uma amostra disso foi o Programa Alfabetização Solidária (PAS), coordenado pela Capacitação Solidária, que revitalizou velhos modelos ineficazes de campanhas emergenciais de alfabetização de jovens e adultos com recursos de doação de empresas e indivíduos, tirando a responsabilidade do Estado e transferindo-a para a sociedade civil. Dentre os diversos problemas que cercavam o PAS podemos citar o conceito restrito de alfabetização, o curto período para os cursos de alfabetização e a falta de uma continuidade de escolarização para os jovens e adultos que finalizavam tais cursos. Ou seja, em linhas gerais e em plena virada de século, o PAS manteve 
vicissitudes recorrentes na história da EJA no Brasil (CARVALHO, 2011).

Eleito em 2002, o governo Lula (2003-2010) trouxe consigo a esperança de que a EPJA pudesse ser valorizada, sendo tratada de forma adequada e com a urgência necessária. Suas principais iniciativas nessa área foram: a criação da Secretaria de Educação Continuada, Alfabetização e Diversidade (SECAD ${ }^{9}$ ) ligada ao MEC; a inauguração de uma série de programas, como o Programa Brasil Alfabetizado, o ProJovem, e o Proeja, de todos, o mais interessante, justamente por integrar a EPJA à educação profissional nos anos finais do ensino fundamental e no ensino médio e por utilizar a estrutura dos institutos federais; e a criação do Fundeb, que passa a abarcar a EJA, em substituição ao Fundef.

Apoiada por Lula, Dilma Rousseff (2011-2016) deu continuidade às ações desenvolvidas na área por seu antecessor. As ações realizadas por Lula e Dilma mostram uma retomada (ou, pelo menos, uma tentativa de retomada) do papel da União na indução das políticas de EPJA. Contudo, não conseguiram alcançar resultados satisfatórios quanto ao atendimento da demanda. Apesar dos avanços e do breve incremento simbólico do lugar ocupado pela EPJA na agenda política do governo, tais gestões não conseguiram, de fato, romper com a concepção de EPJA elaborada no âmago das reformas neoliberais do Estado e da educação, que perpassaram a década de 1990. A repercussão disso pode ser identificada na fragmentação, sobreposição e pulverização de ações, projetos ou programas para a EPJA, que continuaram regidos pela lógica da parceria "conciliatória", cujos resultados não serviram para constituir uma política pública de Estado com efetividade social ou para reverter o cenário de marginalização.

Michel Temer (2016-2018) e Jair Bolsonaro (2019-em andamento) desprezaram essa modalidade educativa. As políticas desenvolvidas por seus antecessores ficaram em segundo plano e não foram inauguradas novas ações para a área. Nesse período, pode-se afirmar que a EPJA acabou ficando quase em sua totalidade

\footnotetext{
${ }^{9}$ Posteriormente, tal Secretaria passou a ser denominada de SECADI, ao acrescentar o tema da "Inclusão" dentro de suas responsabilidades.
} 
sob gestão das administrações estaduais e municipais. No governo Temer, um dos principais ataques foi a aprovação da Resolução do Conselho Nacional de Educação no 3/2018, que, ao atualizar as Diretrizes Curriculares Nacionais para o Ensino Médio, previa o oferecimento de até $80 \%$ da carga horária dos cursos de EJA a distância.

A redução de programas e de políticas públicas, acrescida da aprovação das reformas trabalhista e previdenciária e da Emenda Constitucional n 95/2016, que congelou os gastos públicos da União (Executivo, Legislativo e Judiciário) por um período de vinte anos, trouxe sérios prejuízos para as camadas mais pobres da população em geral, demandantes de EPJA -, deixando um grande contingente de pessoas em condições mais extremas de vulnerabilidade social ${ }^{10}$.

Uma das primeiras medidas tomadas por Bolsonaro foi a extinção da SECADI, atingindo diretamente as políticas de EPJA. No lugar, foram criadas duas novas secretarias: a Secretaria de Alfabetização e a Secretaria de Modalidades Especializadas da Educação. No entanto, não consta no decreto que as instituiu a criação de nenhuma diretoria específica dedicada à modalidade. Cabe destacar que a SECADI era responsável não apenas por coordenar a EPJA, mas também a Educação do Campo e a Educação nas Prisões, modalidades de educação cujo público frequentemente é também estudante da EPJA.

No Decreto $n^{\circ}$ 9.765/2019, que institui a atual Política Nacional de Alfabetização, a EPJA é citada apenas uma vez quando se faz menção ao desenvolvimento de materiais didáticopedagógicos para a modalidade. Contudo, desde 2016, o Programa Nacional do Livro Didático não distribui livros específicos como a modalidade requer. Ou seja, as políticas educacionais para a população jovem e adulta foram praticamente abandonadas pelo governo federal.

Para que a população jovem e adulta possa ter o seu direito humano à educação ao longo da vida garantido, seguem alguns desafios: 1) a necessidade de garantir um maior controle social de

10 Segundo estudo técnico da Consultoria de Orçamento da Câmara dos Deputados, apenas para a área educacional pública, a perda de recursos financeiros seria na ordem de mais de $R \$ 25$ bilhões por ano. 
acompanhamento e cobrança na utilização dos recursos do Fundeb; 2) a importância de pautar um debate que reivindique o fim de programas fragmentados para a EPJA, que não têm efetividade e esvaziam as políticas; 3) a necessidade de construção de uma política pública nacional para a EPJA; 4) uma maior fiscalização pelos poderes públicos e pelos fóruns de EJA na aplicação dos recursos do FPM e do Fundeb nessa modalidade educativa; 5) a garantia de que os programas migrem para as redes municipais de educação e as matrículas sejam feitas através da EJA, garantindo assim 0 acompanhamento por docentes concursados; e, por último, 6) a necessidade de tratamento isonômico da EJA no Fundeb, quer dizer, igualar o fator de ponderação das matrículas de estudantes jovens e adultos ao do ensino regular.

\section{EDUCAÇÃo PARA O TRABALHO OU EDUCAÇÃO PARA A CLASSE TRABALHADORA?}

Considerando a trajetória histórica da EPJA no Brasil, conforme exposto na seção anterior, pode-se perceber que esta modalidade de ensino foi construída a partir de visões políticas diversas, por vezes caracterizadas por ofertas residuais e práticas fragmentadas, imersas em programas suplementares e descontínuos.

Os programas voltados à EPJA devem considerar que seu público é heterogêneo, possui perfil diferenciado em relação à idade, origem, expectativas e interesses. Sabe-se que a EPJA é formada por jovens, adultos e idosos excluídos, quer seja pela dificuldade de acesso à escola, em que pesem as questões socioeconômicas, quer seja pela não continuidade no ensino regular.

Neste sentido, a prioridade dada à educação das crianças e adolescentes (educação infantil e ao ensino fundamental regular), não menos importante que a EPJA, tem marginalizado as ações educacionais voltadas ao público jovem/adulto que, cada vez mais, ocupam lugar secundário no interior das políticas educacionais.

Isto posto, convém esclarecer que quando se interroga acerca da defesa de uma educação para a classe trabalhadora, questiona-se, portanto, uma educação que seja voltada para o trabalho ou para 
uma lógica reificada de exploração da mão de obra do/a trabalhador/a, cujas atividades estão restritas à discussão rasa dos direitos trabalhistas, ou sem a reflexão adequada sobre a identidade, os papéis social e político de jovens e adultos na sociedade.

Assim, considerando que a "classe trabalhadora" é o público majoritário da EPJA, não podemos prescindir da análise de que a distribuição desigual de oportunidades educacionais continua a ter como pano de fundo as desigualdades socioeconômicas, geradas a partir das assimetrias de poder daí advindas. Portanto, falar de EPJA é dialogar imanentemente com a questão de classe:

\begin{abstract}
A Educação de Jovens e Adultos (EJA), regulamentada como modalidade de ensino, é, sem dúvida, uma educação de classe. Assim, se configura, no Brasil, como oferta de possibilidades de elevação da escolaridade para aqueles aos quais foi negado o direito à educação na fase da vida historicamente considerada adequada. É, mais precisamente, uma educação para as frações da classe trabalhadora cujos papéis a serem desempenhados no cenário produtivo não requerem maiores investimentos do estado [...] (RUMMERT, 2007, p. 38).
\end{abstract}

Nesse sentido, para compreender a EPJA, temos que considerá-la como síntese de múltiplas determinações. Vale também precisar o sentido das "determinações". Determinações são traços pertinentes aos elementos constitutivos da realidade; nas palavras de um analista, para Marx, a determinação é um "momento essencial constitutivo do objeto" (DUSSEL, 2012, p. 32-33).

Assim, é por meio da ação do homem sobre a natureza que ele produz sua própria existência e, de modo não muito diferente, produziu a concepção de classe, reafirmando esta como fenômeno histórico. Por conseguinte, a apropriação do conceito de classe social correspondente ao seu período histórico é desenvolvida por Thompson (2002, p. 57), ao afirmar que:

[...] nenhuma categoria histórica foi mais incompreendida, atormentada, transfixada e deshistorizada do que a categoria de classe social; uma 
formação histórica autodefinidora, que homens e mulheres elaboram a partir de sua própria experiência de luta, foi reduzida a uma categoria estática, ou a um efeito de uma estrutura ulterior, das quais os homens não são os autores, mas os vetores.

Converge para esse entendimento o que nos diz Marx (2009, p. 125): "o moinho movido pelo braço humano nos dá a sociedade com o suserano; o moinho a vapor dá-nos a sociedade com o capitalista industrial". Portanto, toda classe social existe a partir de uma correlação de poder, não é uma coisa em si mesma.

Voltando à EPJA, no que se refere à sua relação com o mundo do trabalho, é importante compreender que as relações de trabalho se estabelecem vinculadas ao sistema econômico vigente, e ao trabalhador, por sua vez, implica que venda sua força de trabalho para sobreviver. Nesta relação, o produto que ele produz não é de sua posse e sim propriedade do capitalista. Por força de trabalho ou capacidade de trabalho, Marx compreende o complexo das capacidades físicas e mentais na corporeidade, na personalidade viva de um homem e que ele põe em movimento sempre que produz valores de uso de qualquer tipo (MARX, 2013).

Em Frigotto (2005, p. 63) temos que:

A força de trabalho expressa sua centralidade ao se transformar em produtora de valores de troca, com o fim de gerar mais lucro ou mais valor aos capitalistas. O trabalho, então, de atividade produtora imediata de valores de uso para os trabalhadores, se reduz à mercadoria força de trabalho e tende a se confundir com emprego.

A classe trabalhadora possui apenas a força de trabalho, que é vendida em troca de pagamento/salário e sobre a qual o capitalista obtém a mais-valia ou mais-valor, isto é, o lucro ou valor gerado pelo trabalho excedente.

A educação possui um papel importantíssimo em contraposição a essa lógica, configurando-se em ferramenta que conscientiza o sujeito, fazendo este reconhecer-se na sociedade, para além de uma peça da engrenagem do Capitalismo. 
Nessa perspectiva, um dos grandes desafios que tem se colocado frente à sociedade moderna são os altos índices de desemprego que assola, inclusive, os países ditos de primeiro mundo. Gentili (2005, p. 52) esclarece que:

A empregabilidade ganhou espaço e centralidade a partir dos anos de 1990, sendo definida como o eixo fundamental de um conjunto de políticas supostamente destinadas a diminuir os riscos sociais do grande tormento do final do século: o desemprego.

Nesse processo, o que se observa é uma classe trabalhadora lutando arduamente para manter-se empregada, sob a ameaça constante do desemprego estrutural, marcadamente presente nas economias capitalistas, haja vista que a força de trabalho que excede as necessidades da produção engendra o desemprego - o exército de reserva.

A história nos mostra que a educação é mais um espaço de disputas hegemônicas, portanto, repleta de conflitos, em especial quando levamos em consideração que essa "hegemonia é construída no processo de conquista e manutenção da direção política, intelectual, moral, cultural e, por isso tudo, também econômica, mediante a obtenção da legitimidade da vontade coletiva, materializada no consenso" (SILVA, 2016, p. 14).

Nesta perspectiva, cabe aos/às educadores/as e à sociedade como um todo buscar a mudança dessa lógica. Sabe-se, porém, que este processo por si só não é suficiente para romper com esta hegemonia, no entanto, é imprescindível, quando o que se quer é uma educação emancipadora e comprometida com a formação social dos sujeitos. Sobre esse ponto:

Limitar uma mudança educacional radical às margens corretivas interesseiras do capital significa abandonar de uma só vez, conscientemente ou não, o objetivo de uma transformação social qualitativa. [...] É por isso que é necessário romper com a lógica do capital se quisermos contemplar a criação de uma alternativa educacional significativamente diferente (MÉSZÁROS, 2008, p. 27). 
O modo de existir e a existência do homem relaciona-se diretamente aos fatores econômicos, pois estes em grande medida a condicionam, isto é, a existência está intrinsecamente ligada ao trabalho, sendo este ligado ao Capitalismo e à sociedade civil.

$\mathrm{Na}$ atualidade, nota-se que a EPJA deixou de ser uma modalidade configurada por um público adulto, passando gradualmente a ter a presença de um número crescente de adolescentes. Embora isso seja notado com mais intensidade atualmente, esse fenômeno não é novo, iniciando-se ainda nos anos de 1990.

A juvenilização é o rejuvenescimento da população que frequenta a EPJA. A presença significativa de jovens, inclusive adolescentes, é o resultado da migração do ensino regular para o ensino da EPJA. Embora a EPJA na composição de sua sigla faça menção aos 'jovens' e 'adolescentes', a modalidade de ensino foi pensada para adultos como forma de reparação da dívida histórica de exclusão escolar.

O fenômeno da juvenilização da EPJA advém de vários fatores, entre eles, os desafios socioeconômicos do seu público, além das questões de acesso ao emprego e à renda, que, por vezes, conduzem o estudante para o mundo do trabalho, de maneira que nem ele próprio se dá conta de que foi "cooptado pelo Capital".

Entre 2018 e 2019, foram aproximadamente 300 mil alunos do $2^{\circ}$ segmento (anos finais do ensino fundamental) e 200 mil alunos(as) que migraram do ensino médio para a EPJA ( $3^{\circ}$ segmento). Esses estudantes possuem em seus históricos escolares retenção e buscam meios para conclusão dos ensinos fundamental e médio.

Nesse sentido, faz-se um alerta: o fato de estudantes estarem deixando de cursar o ensino fundamental (dentro da relação ano escola/faixas etárias esperadas) para se inserirem na EPJA, que nos indica $O$ insucesso da escola regular. Converge para esse entendimento o que nos diz Furtado (2015, p. 55): "[...] é resultado também desse processo de escolarização degradada, que perpetua a exclusão escolar. Os/as alunos/as têm acesso ao espaço físico, mas não a uma educação de qualidade, que os/as considere como sujeitos de direitos". Portanto, trata-se de falha nas políticas públicas voltadas para a Educação Básica. 


\section{CONTRADIÇõES E POSSIBILIDADES NA EPJA}

Levando em consideração a necessidade de se identificar o que mais concretamente representa a EPJA, não podemos prescindir da análise de que ela é formada por pessoas, e essas pessoas constituem a população numa sociedade que está em constante transformação, assim, cabe-nos falar das pessoas que compõem a EPJA.

A proposta educacional para a EPJA confeccionada por Paulo Freire fundamentava-se na categoria dialética da prática social. Assim, a prática social, para o Materialismo Dialético, é uma categoria histórica, além de critério de verdade para todo conhecimento, por se configurar em fenômeno material que possibilitou a evolução do ser humano do estágio de ser meramente biológico para o estágio de ser racional. Na perspectiva de Freire (2005), sob o manto do Materialismo Dialético, o homem é ser histórico, isto é, ser para si, o que o coloca numa "postura decisória frente ao mundo, do qual o ser se 'separa', e, objetivando-o, o transforma com sua ação" (FREIRE, 2005, p. 105).

Para Arroyo (2012, p. 76), "defender o direito dos trabalhadores à educação é uma proposta mais radical do que apenas defender escola para todos". Assim, nota-se que os avanços que ocorrem nos países ricos tardam a chegar nos países pobres, representando em si a contradição do sistema:

A escola onde todos passam um tempo cada vez mais longo, passou a fazer parte da lógica da sociedade capitalista e hoje, nos países avançados, constitui um dos mecanismos usados para distribuir cada um no seu lugar, no lugar que por capacidade e mérito comprovado e atestado lhe corresponde na divisão do trabalho. Entretanto, o direito à educação, os avanços das classes trabalhadoras na formação do saber, da cultura e da identidade de classe continuam sendo sistematicamente negados, reprimidos e, enquanto possível, desestruturados, por serem radicalmente antagônicos ao movimento do capital (ARROYO, 2012, p. 77-78). 
Assim, ao conceber a sociedade capitalista como sendo estruturalmente erguida a partir de suas próprias contradições, percebe-se que a EPJA é uma genuína expressão das contradições, visto que a Educação como um todo se configura em arena de disputas hegemônicas.

A educação brasileira historicamente forjou-se na/da exclusão em todos os níveis e modalidades de ensino, sobretudo porque é por meio da educação que se tem estruturado privilégios às elites, que têm mais acesso a uma melhor formação possível, restando às classes populares uma escolarização, via de regra, precária e aligeirada, de caráter compensatório em vez de uma educação emancipatória.

Coadunando com esse entendimento, Saviani (2008, p. 55) afirma que a política e a educação são faces opostas da mesma moeda: a prática social. O autor ainda alerta que "dominar o que os dominantes dominam é condição de libertação". Neste sentido, é indispensável a participação política da população. Contudo, sob uma perspectiva sistêmica, a EPJA deve ser concebida como parte da história da educação do País, e, como tal, uma modalidade importante no processo de democratização do direito à educação (DI PIERRO; JOIA; RIBEIRO, 2001).

A gestão do saber na atualidade tem ocorrido pelo estrito interesse do Capital, e a democratização da escola brasileira organizou-se pela via da resistência da classe dominada. Assim sendo,

se a lógica do capital é a distribuição desigual do saber, a escola presta um serviço à classe trabalhadora, e não ao capital, ao formular propostas pedagógicas que democratizem o saber sobre o trabalho. Contrariamente, ao articular-se às necessidades do mercado de trabalho, serve ao capital (KUENZER, 1992, p. 31).

Nesse sentido, é preciso reconhecer que a história da educação no Brasil tem sido marcadamente dual e dicotômica, isto é, produz-se uma educação destinada à classe dominante e outra destinada à formação de trabalhadores. Como expressão dessa dualidade, herdada das contradições que, ao longo do tempo, 
forjaram nossa cultura educacional, amargamos desigualdades que, inclusive, demonstram como algumas modalidades de ensino enfrentam a imposição de um "não lugar" na agenda de prioridades da educação nacional. Como exemplo disso, temos a EPJA - fato esse que se comprova com a primeira versão da Base Nacional Curricular Comum (BNCC), lançada em 2015, em que a EPJA não é citada em sua especificidade.

Esta ausência chama a atenção, porque a Educação de Jovens e Adultos (EJA) é uma modalidade de ensino da Educação Básica. O texto da BNCC limitou-se a informar que determinados eixos e conteúdos se aplicam a crianças, jovens e adultos, sem que houvesse qualquer reflexão sobre a especificidade da modalidade, tendo em vista os seus sujeitos. Nesse contexto, cabe um alerta para a inexistência da EJA no documento proposto:

Como compreender os impactos que a BNCC aprovada causa nos processos de gestão dos sistemas de ensino e das escolas? O primeiro elemento a considerar é o rompimento com a concepção de Educação Básica insculpida na LDB, uma vez que o CNE foi levado a considerar a aprovação de proposta incompleta encaminhada pelo MEC sem contemplar o ensino médio, sem a modalidade Educação de Jovens e Adultos e sem a Educação do Campo, além de outras fragilidades (MENDONÇA, 2018, p. 36).

Essa ausência foi tema de debates em diversos encontros e em diferentes contextos. As críticas direcionadas ao modo como se organizava a BNCC afunilavam para o entendimento de que o proposto era inadequado ao público da EPJA. Mesmo que fosse possível pensar em conteúdos comuns a todas as pessoas que são certificadas nas diferentes modalidades da Educação Básica, existem muitos elementos a serem considerados para a garantia da equidade, ou seja, do direito de todos aos mesmos "direitos de aprendizagem", fazendo-se uso dos termos da BNCC.

Seguindo esse viés do "não lugar" a que foi relegada a EPJA nos documentos regentes, é importante mencionar que no Plano Nacional de Educação (PNE 2014-2024) (Lei nº 13.005/2014) inexiste 
um olhar específico para a EPJA. No texto desta Lei, das 20 metas que a constitui, quatro dizem respeito diretamente ao atendimento escolar de adolescentes, jovens e adultos (3, 8, 9 e 10), entretanto, de forma muito genérica.

A EPJA é formada por trabalhadores/as que, motivados/as pela esperança na educação, buscam melhores condições de vida. Eles vão para a escola repletos de sonhos e saberes, porém, algumas vezes, as escolas desconsideram os saberes do cotidiano desse/a estudante, negando-lhes a possibilidade do aprimoramento a partir desses conhecimentos que estão mais próximos de suas realidades.

O vínculo com o trabalho é uma importante característica a ser destacada em relação aos sujeitos da EPJA, seja por serem filhos de trabalhadores, por estarem em busca de emprego ou por já fazerem parte do mundo do trabalho. $O$ trabalho ocupa o espaço da prioridade. São sujeitos de múltiplos saberes que foram constituídos no percurso de suas histórias e experiências de vida, marcadas por descontinuidades que ficam evidentes em seus percursos escolares.

Assim, o estudante da EPJA, ao retornar à escola, passa a se perceber no mundo à medida que eleva sua escolaridade por meio da aquisição do conhecimento formal, compreende o mundo nas suas dimensões social, cultural e econômica, além de alargar a possibilidade de uma qualificação profissional integrada à formação propedêutica. Neste contexto, a EPJA só faz sentido quando se interessa efetivamente pela emancipação do sujeito na sociedade, e não apenas no processo meramente instrucional.

\section{CONSIDERAÇÕES FINAIS}

Passados mais de trinta anos da conquista constitucional dos jovens e adultos à escolarização e após inúmeros projetos, ações e programas nacionais de EPJA realizados nas últimas décadas, ela continua desconsiderada, tratada como uma política pública educacional de segunda linha. Embora o arcabouço legal Ihe garanta, a realidade confere status inferior nas políticas educacionais, 0 imaginário social a apreende como modalidade em processo de extinção, como algo apenas do passado, o que é um grande absurdo, afinal, em nosso país, temos mais de 80 milhões de pessoas que são 
potenciais demandantes de EPJA, uma vez que não terminaram a educação básica.

Apesar de a Constituição Federal de 1988, em seu art. 205, definir a educação como um direito de todos, o que observamos são programas desenhados a partir de projetos frágeis e fragmentados, com problemas que vão desde a concepção pedagógica e metodológica, até a estrutura e a organização. Como consequência de longos períodos de exclusão, da falta de reconhecimento jurídicosocial demonstrado pelo processo histórico e da omissão do Estado, a EPJA não foi e nem é uma das prioridades educacionais do País. Esta modalidade de ensino ainda não representa um processo de emancipação e de transformação social e as contradições entre trabalho, educação e o modo de produção capitalista ainda persistem.

Ainda que o Brasil tenha assinado a Declaração Mundial sobre a Educação para Todos, na Conferência Mundial sobre Educação para Todos em Jomtien (Tailândia, 1990), ainda não assumiu efetivamente compromisso político com o direito humano à educação das pessoas jovens e adultas.

O que temos assistido nas últimas três décadas é a ineficiência do Estado, atuando de forma marcadamente desigual, produzindo contradições a cada novo programa instituído, além da falta de integração entre outras políticas. Neste âmbito, muitos programas surgem como alternativas assistencialistas de combate à exclusão social, com propostas pedagógicas que sugerem uma forma universalizada de trabalho, sem levar em conta as peculiaridades locais de cada comunidade.

Interessa demarcar, também, que as políticas de EPJA no Brasil - enquanto questão de classe - caracterizam-se constantemente por ofertas residuais, frágeis e descontínuas, sem que os problemas e contradições presentes em sua materialidade sejam efetivamente vencidos com vistas ao alcance de uma educação verdadeiramente emancipatória, configurando-se assim, um perpétuo ciclo de negação da educação com qualidade à classe trabalhadora. Tratam-se, portanto, de problemas amplos, que se encontram envoltos em uma totalidade historicamente contraditória. 
Conforme observamos, as consequências de longos períodos de exclusão e marginalização da EPJA, evidenciadas pelo processo histórico descrito neste texto, demonstram omissão do Estado brasileiro para com a EPJA. Os programas federais de caráter aligeirado e compensatório representam arranjos da mesma lógica que marcou as políticas para essa modalidade no país: atender as necessidades de sociabilidade do próprio capital, bem como amenizar as tensões sociais e os males que o sistema capitalista proporciona.

A educação deve ser compreendida como fenômeno historicamente situado, o qual não pode ser analisado por partes isoladas, isto é, fora da compreensão de sua totalidade, nem apartado de uma historicidade, tampouco sem se considerar as contradições que a envolve. Logo, o real é sempre fruto da mudança, ou seja, do combate entre os contrários. Tudo é regido pela dialética, a tensão e o revezamento dos opostos.

Em face do exposto, pode-se constatar que o atual estado de conformação da EPJA não é vazio de intencionalidade, pelo contrário, tem representado um esforço dos governos, sob pressão dos organismos internacionais, para enfrentar dois problemas da sociedade dita globalizada: a baixa produtividade e o desemprego estrutural. O predomínio de uma concepção produtivista nas atuais políticas educacionais, ao mesmo tempo em que se baseia no discurso da equidade e democratização, estimula a exclusão de determinadas modalidades de ensino por meio de desobrigação governamental. É dessa forma que a EPJA vem sendo dimensionada no contexto social.

Os movimentos sociais que lutam pelo direito humano à educação, com boa qualidade social para os jovens e adultos, devem continuar pressionando os poderes públicos, precipuamente as redes públicas estaduais e municipais de educação, para que as políticas públicas de EPJA sejam configuradas ou construídas com base em uma perspectiva curricular de educação popular, emancipatória e de trabalho não alienado, contribuindo para a ampliação de uma concepção de formação humana integral, de preferência, articulada à educação profissional. 
Nesse sentido, precisamos escrever uma nova história para a educação no Brasil, sobretudo para a EPJA. E reconhecermos que a educação é, por via de regra, o caminho necessário e possível para se chegar efetivamente a um novo projeto de país; emancipatório, reconhecedor dos direitos humanos e da diversidade dos sujeitos históricos que compõem a sociedade brasileira.

\section{REFERÊNCIA}

ARELARO, Lisete R. G.; KRUPPA, Sônia M. P. A Educação de Jovens e Adultos. In: OLIVEIRA, Romualdo P.; ADRIÃO, Theresa (orgs.).

Organização do ensino no Brasil: níveis e modalidades na Constituição Federal e na LDB. São Paulo/SP, Editora Xamã, 2002.

ARROYO, M. Educação de Jovens e Adultos: Um campo de direitos e de responsabilidade pública. In: GIOVANETTI, M. A.; GOMES, N. L.; SOARES, L. (Orgs.). Diálogos na Educação de Jovens e Adultos. Belo Horizonte: Autêntica, 2005. p. 19-50.

ARROYO, M. O direito do trabalhador à educação. In: GOMEZ, Carlos M. et al. Trabalho e conhecimento: dilemas na educação do trabalhador. 2. ed. São Paulo: Autores Associados, 2012.

BRASIL. Censo Escolar da Educação Básica 2019: resumo técnico. Brasília, DF: Instituto Nacional de Estudos e Pesquisas Educacionais Anísio Teixeira, 2019. Disponível em: http:// http://portal.inep.gov.br/informacao-da-publicacao//asset_publisher/6JYIsGMAMkW1/document/id/6874720 Acesso em: 17 jul. 2021.

BRASIL. Censo Escolar da Educação Básica de 2020: resumo técnico. Brasília, DF: Instituto Nacional de Estudos e Pesquisas Educacionais Anísio Teixeira Disponível em: https://download.inep.gov.br/censo_escolar/resultados/2020/aprese ntacao_coletiva.pdf. Acesso em: 26 jul. 2021

BRASIL. Constituição da República Federativa do Brasil. Brasília/DF, 05 de outubro de 1988. 
BRASIL. Decreto n 9.765, de 11 de abril de 2019. Institui a Política Nacional de Alfabetização. Diário Oficial da União, Brasília, DF, 11 abr. 2019a. Disponível em:

http://www.planalto.gov.br/ccivil_03/_ato2019-

2022/2019/decreto/D9765.htm. Acesso em: 17 jul. 2021.

BRASIL. Emenda Constitucional n 95, de 15 de dezembro de 2016. Altera o Ato das Disposições Constitucionais Transitórias, para instituir o Novo Regime Fiscal, e dá outras providências. Diário Oficial da União, Brasília, DF, 15 dez. 2016. Disponível em:

http://www.planalto.gov.br/ccivil_03/constituicao/emendas/emc/em c95.htm. Acesso em: 17 jul. 2021.

BRASIL. Lei no 13.005 de 25 de junho de 2014. Aprova o Plano Nacional de Educação - PNE e dá outras providências. Diário Oficial da União, Brasília, DF, 26 jun. 2014. Disponível em:

http://www.planalto.gov.br/ccivil_03/_ato2011-

2014/2014/lei/l13005.htm. Acesso em: 17 jul. 2021.

CARVALHO, Marcelo P. As políticas para a Educação de Jovens e Adultos nos governos Lula (2003-2010): incongruências do financiamento insuficiente. 349f. 2011. Tese (Doutorado em Educação) - Universidade de São Paulo. São Paulo, 2011.

DI PIERRO, Maria. C.; JOIA, Orlando.; RIBEIRO, Vera. M. Visões da educação de jovens e adultos no Brasil. Caderno Cedes, ano XXI, n. 55, p.58-77, nov. 2001.

DUSSEL, E. A produção teórica de Marx: Um comentário aos Gründrisse. 1. ed. São Paulo: Expressão Popular, 2012.

FREIRE, Paulo. Pedagogia da Autonomia: saberes necessários à prática educativa, 21. ed., São Paulo/SP: Paz e Terra, 2002.

FREIRE, Paulo. Pedagogia do Oprimido. Rio de janeiro: Paz e Terra, 2005.

FRIGOTTO, G. Concepções e mudanças no mundo do trabalho e o ensino médio. In: Gaudêncio Frigotto; Maria Ciavatta; Marise Ramos. (Org.). Ensino Médio Integrado: Concepção e contradição. 1ed.São Paulo: Cortez, 2005. 
FURTADO, Q. V. F. Jovens na educação de jovens e adultos:

produção do fracasso no processo de escolarização. João Pessoa:

Editora Universitária/UFPB, 2015.

GADOTTI, M.; ROMÃO, J. E. Educação de jovens e adultos: teoria prática e proposta. 8. ed. São Paulo: Cortez, 2013.

GENTILI, Pablo. Três teses sobre a relação trabalho e educação em tempos neoliberais. In: LOMBARDI, José Claudinei; SAVIANI, Dermeval; SANFELICI, José Luis (Org.). Capitalismo, trabalho e educação. 3. ed. Campinas: Autores Associados, HISTEDBR, 2005. p. 45-59.

HADDAD, Sérgio; DI PIERRO, Maria C. Escolarização de Jovens e Adultos. Revista Brasileira de Educação, 500 anos de Educação Escolar, n. 4, Editora Autores Associados, 2000.

HADDAD, Sérgio. Estado e Educação de Jovens e Adultos (19641985). Tese (Doutorado em Educação) - Universidade de São Paulo. São Paulo, 1991.

HADDAD, Sérgio. A Educação de Jovens e Adultos e a nova LDB. In: BRZEZINSKI, Iria (org.). LDB Interpretada: diversos olhares se entrecruzam. 5. ed. São Paulo/SP, Cortez Editora, 2001.

HADDAD, Sérgio. Educação de Jovens e Adultos no Brasil (19861998). Brasília/DF, MEC/INEP/COMPED, 2002. (Série Estado do Conhecimento)

IBGE. Pesquisa Nacional por Amostra de Domicílios (PNAD) 2019. Disponível em: < https://www.ibge.gov.br>. Acesso em: acesso em: 17 jul. 2021.

KUENZER, Acácia Z. Ensino de $\mathbf{2}^{\circ}$. Grau - o trabalho como princípio educativo. São Paulo: Cortez, 1992.

MARX, K. Miséria da filosofia: resposta à Filosofia da miséria, do Sr. Proudhon. São Paulo: Expressão Popular, 2009.

MARX, K. O Capital: crítica da economia política: Livro I: o processo de produção do capital; [tradução de Rubens Enderle]. São Paulo: Boitempo, 2013. 
MARX, Karl; ENGELS, Friedrich. A Ideologia Alemã. Tradução de Luís Claudio de Castro e Costa. São Paulo: Martins Fontes,1989.

MENDONÇA, Erasto Fortes. PNE e base nacional comum curricular (BNCC): Impactos na gestão da educação e da escola. In: AGUIAR, Márcia Angela da S.; DOURADO, Luiz Fernandes (orgs.). A BNCC na contramão do PNE 2014-2024: avaliação e perspectivas. Recife: ANPAE, 2018.p. 34-37.

MÉSZÁROS, I. Para além do Capital: rumo a uma teoria da transição. São Paulo: Boitempo, 2008.

ROMANELLI, Otaíza de Oliveira. História da Educação no Brasil (1930-1973). Petrópolis: Editora Vozes, 1986.

RUMMERT, S. M. Gramsci, trabalho e educação: jovens e adultos pouco escolarizados no Brasil actual. Lisboa: Olímpio Ferreira, 2007.

SAVIANI, Dermeval. Escola e democracia. Edição comemorativa. Campinas, SP: Autores Associados, 2008.

SILVA, Deise Rosalio. Hegemonia e educação: teoria e prática para a mudança política. Trabalho apresentado na $1^{\text {a }}$ Jornada internacional de estudos e pesquisas em Antônio Gramsci - JOINGG. Fortaleza: Universidade Federal do Ceará, 2016. p. 12-35.

THOMPSON, E.P. Educação e experiência. In: Doroty Tompson (Org.). Os Românticos: a Inglaterra na era revolucionária. Tradução de Sergio Moraes Rego Reis. Rio de Janeiro: Civilização Brasileira, 2002

Submetido em: Julho/ 2021.

Aceito em: Agosto/ 2021. 